\title{
A TREATMENT OF TOXIC SUBSTANCE IN PHARMACEUTICAL INDUSTRY WASTEWATER: A REVIEW
}

\author{
P. Mukesha ${ }^{1}$, S.Srinivasamurthyb ${ }^{2}$, P.S. Vigneshkumarb ${ }^{3}$, P.Balamurugana ${ }^{4}$ \\ ${ }^{1,4}$ Assistant Professor, Department of Civil Engineering, M. Kumarasamy College of Engineering, Karur, Tamil Nadu, India \\ ${ }^{2,3}$ UG Scholar, Department of Civil Engineering, M. Kumarasamy College of Engineering, Karur, Tamil Nadu, India
}

\begin{abstract}
Pharmaceutical compounds are emerging environmental issue due to their continuous input and persistence to aquatic ecosystem even at low trace concentration. The aim of the present review is to find the effective way to reduce the pollutants in the pharmaceutical wastewater. There are several studies in the aim to develop new processes and new technologies to minimize the volume and toxicity of effluents generated by pharmaceutical industry wastewater. It demonstrates that Advanced oxidation process in a system can be a promising technology to treat pharmaceutical wastewater characterized by simultaneous presence of biodegradable and refractory inhibitory compounds.
\end{abstract}

Keywords: Pharmaceutical compounds, Environmental issue, Toxicity Effluents, Advanced oxidation process, Inhibitory compounds.

\section{Introduction}

Water resource are wellsprings of water that are helpful or conceivably valuable to people (Balamurugan and Balakumaran 2015; Balamurugan and Kumar 2016). It is significant on the grounds that it is required for life to exist. Numerous employments of water incorporate farming, modern, family unit, recreational and ecological exercises (Balamurugan and Shunmugapriya 2019; Balamurugan et al. 2020a). Basically these human uses require new water. Just $2.5 \%$ of water on the Earth is new water, and more than $66 \%$ of this is frozen in icy masses and polar ice covers (Kumar and Balamurugan 2018; Kumar and Balamurugan 2019). Water request as of now surpasses flexibly in numerous pieces of the world, and a lot more regions are relied upon to encounter this awkwardness soon. It is assessed that $70 \%$ of world-wide water use is for water system in agribusiness (Balamurugan and Vinnilavu 2020b; Balamurugan et al. 2020c; Balamurugan et al. 2018). Environmental change will affect the water resource around the globe in view of the relations between the atmosphere and hydrologic cycle. Because of the extending human population rivalry for water is becoming with the end goal that a significant number of the worlds significant springs are getting exhausted (Panneerselvam et al. 2020a; Panneerselvam et al. 2020b). Numerous toxins compromise water supplies, however the most widespread, particularly in immature nations, is the discharge of crude sewage into regular waters (Balamurugan et al. 2020d) .

Wastewater is utilized water. It incorporates substances, for example, human waste, food scraps, oils, cleansers and synthetic compounds. In homes, this incorporates water from sinks, showers, baths, latrines, clothes washers and dishwashers (Shunmuga Priya and Balamurugan 2020d). Businesses and industries likewise contribute a lot of utilized water that must be cleaned. Nature has an astounding capacity to adapt to limited quantities of water wastes and contamination, however it would be overpowered in the event that we didn't treat the billions of gallons of wastewater and sewage delivered each prior day delivering it back to the climate. Treatment plants decrease poisons in wastewater to a level nature can deal with. Wastewater likewise incorporates storm spill over. Albeit a few people accept that the downpour that runs down the road during a tempest is genuinely spotless, it isn't. Unsafe substances that wash goes romping, parking areas, and housetops can hurt our streams and lakes(Vinnilavu and Balamurugan 2019).

Pharmaceutical waste is one of the major complex and toxic industrial wastes (Ashfaq and Khatoon 2014). Most pharmaceutical substances are by nature biologically active and hydrophilic in order that the human body can take them up easily and persistent to avoid degradation before they have a curing effect. The pharmaceutical industry employs various processes and a wide variety of raw materials to produce an array of final products needed to fulfill national demands (Kumar et al. 2016). Generation of wastewater in industrial processes is sometimes unavoidable and in most of the cases a process to reduce the organic load. To remove part of the organic load biological processes are usually used because they are more economic than chemical processes. Many researchers have tried to find out different treatments for pharmaceutical wastewater to approaches worldwide; here an attempt is made to review some such researches done with particular reference to Pharmaceutical wastewater effluent in India and abroad also(Varatharajan and Kanmani 2007) .

Pharmaceutical wastewater streams can be difficult to treat with conventional physical/chemical and biological treatment systems. High chemical oxygen demand (COD) variable 
strength waste streams and shock loads are just a few of the conditions that limit the effectiveness of these conventional systems. Additionally in some cases water may have been formed as part of a chemical reaction (Chelliapan and Sallis 2013). The process wastewater generated by the production processes contains a variety of conventional parameters (e.g. BOD TSS and $\mathrm{pH}$ ) and other chemical constituents. The degradation of pharmaceuticals and their residues is of particular interest due to the ubiquity of these compounds and to their capacity of affecting aquatic organisms even if they exist at trace concentrations. With increasing water scarcity and reuse practices the concentration of pharmaceuticals and their residues in the aquatic environment are expected to increase. In this contest segregation and efficient treatment of the wastewaters deriving from pharmaceutical production is highly desired in order minimize this points source of pollution avoiding direct or indirect discharge of drugs and other production chemicals into the sewer.

The contamination of water by refractory organic substances significantly affects the viability of water reuse of treated municipal or industrial water effluents. Historically compounds as substituted phenols non-biodegradable chlorinated solvents pesticides and surfactants are recognized as examples for relevant substances difficult to remove from water(Tchobanoglous et al. 1991). Recently pharmaceuticals and personal care products (PPCPs) and especially endocrine disrupting chemicals (EDCs) are considered as emerging contaminants which means that they are still unregulated or in process of regularization. Moreover low concentrations can elicit adverse effects on aquatic life. Pharmaceuticals enter the environment from a myriad of scattered points. The main sources of contamination include pharmaceutical production plants WWTPs hospitals landfills and even graveyards. Pharmaceutical effluent contains lot of analgesic antibiotics cardiovascular drugs etc. There is no proper treatment for the removal of pharmaceutical pollutant. Thus in order to reduce the crisis for the treatment of pharmaceutical effluent made out a bigger scope nowadays. The removal of residual pharmaceutical compounds from industrial pharmaceutical wastewater is very challenging due to:-

- $\quad$ Presence of non-biodegradable solvents and synthesis intermediate

- The simultaneous presence of high fraction of easily biodegradable carbon and lower amounts of recalcitrant organics

- $\quad$ A high saline content.

The purpose of the current review is to take stock of effluent rising from different sectors of active pharmaceutical ingredients(API) bulk drugs and related pharmaceutics which use large quantities of water to propose strategies to recover to a large extent the valuable compounds to demonstrate the economic benefit of recovery and finally to discuss the treatment of very dilute but detrimental
wastewaters(Nithyanandam and Saravanane 2013). Biological treatment has several advantages over physico-chemical options in treating such wastes apart from its ease of handling and economic feasibility

\section{Treatment Of Pharmaceutical Wastewater}

The pharmaceutical industry requires consistent high-quality water for production and wastewater treatment to meet the demands of ever-stricter regulatory discharge limits. To meet these challenges companies must question conventional thinking and typical approaches and explore new technologies and solutions to remain competitive (Munter R. 2001). A lot of research papers have been published on the treatment of PhPs EDCs and pharmaceuticals and household consumer products (PHCPs) in the past decade mainly dealing with the effluent from tertiary WWTPs. However, treatment options at the source not only could reduce costs and environmental impact but also provide potential recovery of compounds. Although much research has been done in this context and many reviews have been published in recent years they lack a complete scenario of the pharmaceutical wastewater composition and treatment technologies.

The pharmaceutical industry employs a wide array of wastewater treatment and disposal methods. Wastewaters generated from these industries vary not only in composition but also in quantity by plant season and even time depending on the raw materials and the processes used in the manufacturing of various pharmaceuticals (Parmar et al. 2015). it is very difficult to specify a particular treatment system for such a diversified pharmaceutical industry. Many alternative treatment processes are available to deal with the wide array of waste produced from this industry but they are specific to the type of industry and associated wastes. General approaches are employed to treat pharmaceutical wastewaters which are physical-chemical treatment by sedimentation floatation and advanced oxidation process and aerobic/anaerobic biological treatment in membrane bioreactors or bio aeration and new hybrid technologies specific to the pharmaceutical industry.

\section{A. Advanced oxidation process}

With the aim to reach better stability and efficiency performance some research has focused on combination as aerobic and advanced oxidation process are viable alternative treatment for the pharmaceutical compounds that are difficult to treat by traditional process(García-Gómez et al. 2014). Oxidation is defined as the transfer of one or more electrons from an electron donor (reductant) to an electron acceptor (oxidant) which has a higher affinity for electrons. Generally AOPs are defined as aqueous oxidation processes which are primarily based on the intermediacy of hydroxyl radical in the mechanism resulting in the destruction of the target pollutant and pharmaceutical compounds. AOPs have been applied to refractory organic compounds found in industrial waste water 
to improve biodegradability and to increase the treatment efficiency(Joshua Amarnath et al. 2015).

The AOPs have proceeded along one of the two routes:

- $\quad$ oxidation with $\mathrm{O}_{2}$ in temperature ranges intermediate between ambient conditions and those found in incinerators Wet Air Oxidation (WAO ) processes in the region of 1-20 $\mathrm{MPa}$ and $200-300{ }^{\circ} \mathrm{C}$ );

- $\quad$ the use of high energy oxidants such as ozone and $\mathrm{H}_{2} \mathrm{O}_{2}$ and/or photons that are able to generate highly reactive intermediates $\mathrm{OH}$ radicals.

Advanced oxidation involves several steps schematized in the figure below and explained as follows:

1. Formation of strong oxidants (e.g. hydroxyl radicals)

2. Reaction of these oxidants with organic compounds in the water producing biodegradable intermediates

3. Reaction of biodegradable intermediates with oxidants referred to as mineralization

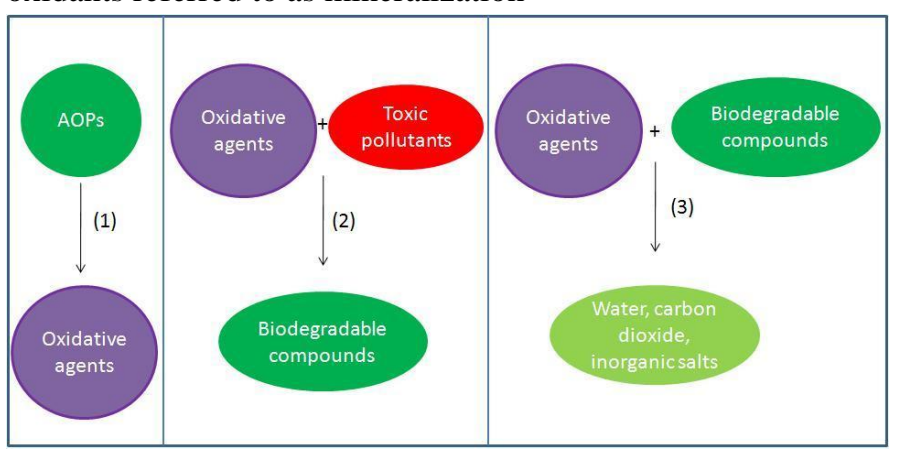

Fig.1 Main steps involved in an AOPs treatment of wastewater containing toxic organic compounds

\section{a) Wet air oxidation}

Wet air oxidation is a thermochemical process where hydroxyl radicals and other active oxygen species are formed at elevated temperatures $\left(200-320{ }^{\circ} \mathrm{C}\right)$ and pressures $(2-20 \mathrm{MPa})$. By using WAO the organic pollutants are either partially oxidized into biodegradable intermediates or mineralized to carbon dioxide water and innocuous end products under elevated temperatures and pressures using a gaseous source of oxygen (either pure oxygen or air) as the oxidant. This technique can also be applied as a pre-treatment process thereby making the wastewater suitable for biological treatment (Elmolla et al. 2012; Esplugas et al. 2007).

\section{b) Ozonation}

Ozone is a very powerful oxidant for water and wastewater treatments and once dissolved in the water reacts with a high number of organic compounds in two different ways: by direct oxidation as molecular ozone or by indirect reaction through the formation of secondary oxidants such as free radicals especially hydroxyl radicals (Kommineni et al. 2008). Ozone has been applied to the treatment of waters primarily due to its strong disinfection and sterilization properties. The main mode of action in the ozonation process is the formation of $\mathrm{OH}$ radicals due to ozone decay in the water. but there are also ozone molecules present for chemical attack. This increases the oxidation capacity (Kanakaraju et al. 2014). Ozonation has been implemented as the principal treatment method or to enhance the biodegradability and efficiency of subsequent treatment. Ozone production is an energy intensive process. making it costly to implement. An ozone treatment system may increase the energy demand over a conventional wastewater treatment plant by $40-50 \%$. The use of ozone as a means of breaking down pharmaceuticals in water has been the subject of numerous studies over the last ten years including However the reported removal rate for lipid regulators is less at about $50 \%$ and about $60-80 \%$ for blockers and below $50 \%$ for some Antiphlogistics although the degree of removal and mineralization of pharmaceuticals in water or synthetic industrial effluent has been reported(Gunasekera et al. 1998).

\section{c) Fenton oxidation}

Fenton's oxidation was one of the best-known metal catalysed oxidation reactions of water-miscible organic compounds. Fenton chemistry involves reactions of hydrogen peroxide in the presence of iron to generate hydroxyl radicals (Klavarioti et al. 2009). Since iron is abundant and non-toxic Fenton reactions are a viable option for wastewater treatment. The Fenton reaction has a short reaction time among all advanced oxidation processes and Iron and $\mathrm{H}_{2} \mathrm{O}_{2}$ are cheap and nontoxic there is no mass transfer limitations due to its homogenous catalytic nature here is no energy involved as catalyst and the process is easily to run and control Since Fenton reactions operate at room temperature normal pressure and without the highly complicated apparatus there should be a smooth transition from laboratory scale to large scale. On the other hand, the strong dependence on the aqueous solution $\mathrm{pH}$ (optimum $\mathrm{pH}$ 2-4 for the production of $\mathrm{OH}$. radicals) and on the concentrations of hydrogen peroxide and ferric / ferrous ions and the disposal of the iron sludge are factors which need to be taken into consideration. The rate of reaction with Fenton's Reagent increases with increasing temperature with the effect more pronounced at temperatures $<20$ deg-C. However, as temperatures increase above 40-50 deg- $\mathrm{C}$ the efficiency of $\mathrm{H} 2 \mathrm{O} 2$ utilization declines. One possibility is the partial use of Fenton reactions to produce a non-toxic and biodegradable intermediate which could then be treated in an inexpensive biological step to achieve complete Mineralisation (Barker 2006; Deegan et al. 2011).

d) Electrochemical oxidation/degradation.

Electrochemical method is based on in situ production of hydroxyl radical $(\bullet \mathrm{OH})$ as the main oxidant which is the second strongest oxidizing agent known after fluorine having such a high standard reduction potential that it is able to nonselectively react with most organic contaminants via hydroxylation or dehydrogenation until their total mineralization. In EAOPs hydroxyl radicals can be generated by direct electrochemistry (anodic oxidation AO) or indirectly through electrochemically generation of Fenton's reagent. In 
the first case _OH are generated heterogeneously by direct water discharge on the anode while in the last case _OH are generated homogeneously via Fenton's reaction (electroFenton EF). Simulated waste having pharmaceutical residues such as diclofenac carbamazepine propranolol ibuprofen and ethinylestradiol treated with electrochemical method has shown complete degradation(Radjenovic et al. 2007). More than $97 \%$ TOC removal has been observed in paracetamol and diclofenac spiked wastewater by boron doped diamond (BDD) electrochemical treatment. The degradation rate of the antibiotic was also enhanced with an increasing concentration of doping boron and decreasing electrode thickness. The efficiency of electro oxidation may be enhanced by the synergetic action of dissolved iron i.e. this technique has been widely proved to be clean flexible and powerful tool to develop new methods for wastewater treatment. All of these processes are based on hydroxyl radical $(\mathrm{OH})$ production which is a powerful oxidant able to react efficiently and nonselectively with several types of refractory organic pollutants.

\section{e) Photo catalysis}

Photo catalysis is the acceleration of a photochemical transformation by the action of catalyst such as $\mathrm{TiO} 2$ or Fenton's reagent.The catalyst which is most commonly employed for all pharmaceutical photocatalytic studies is rutile TiO2. Photocatalysis is the best suited process for effluents having a high COD and for complete transformation of highly refractory organic contaminants to reach biological treatment level(Shariati et al. 2010). In the context of pharmaceutical treatment it has also been reported that for the degradation of sulfamethazine and chloramphenicol respectively $\mathrm{ZnO}_{2}$ showed higher catalytic activity than $\mathrm{TiO}_{2}$. Photocatalytic reactions usually obey the Langmuir-Hinshelwood kinetic model which is reduced to pseudo-first- or zero-order kinetics depending on the operating conditions. The use of $\mathrm{UV} / \mathrm{TiO}_{2}$ along with $\mathrm{H}_{2} \mathrm{O}_{2}$ has shown enhanced removal efficiency of phenols and COD from fermentation effluent. Also a combination of photocatalysis with ozonation has also shown improvement of COD removal in penicillin formulation effluent. Optimal operational conditions and degradation pathways vary with different pharmaceutical compounds. The main conclusion is that the use of $\mathrm{TiO} 2$ photocatalysis can be considered a state-of-the-art pharmaceutical wastewater treatment methodology. Further studies are however required to optimize the operating conditions for maximum degradation of multiple pharmaceuticals in wastewater under realistic conditions and on an industrial scale. Electrocoagulation coupled with photocatalysis has shown $86 \%$ COD removal efficiency in chemical synthesis based wastewater(LaPara et al. 2001). The use of photocatalysis enhances the degradation capability. A novel semiconductor photocatalysis by using a combination of $\mathrm{TiO} 2$ with $\mathrm{RuO}_{2}-\mathrm{IrO}_{2}$ as anode and chloride as an electrolyte has also shown 95\% COD removal with firstorder kinetics. From an economic point of view photocatalysis can be carried out by the usage of solar irradiation and much research has been done in this regard for the treatment of pharmaceutical effluents. Photocatalytic process is also found to be highly energy efficient with consumption of $17 \mathrm{kWh} /(\mathrm{kg}$ of COD removed).

\section{B. Biological treatment}

Wastewaters produced from pharmaceutical industries pose several problems for successful biological treatment. These wastewaters contain relatively high levels of suspended solids and soluble organics many of which are recalcitrant. Following are the biological treatments available to treat the wastewater(Jelić et al. 2012; Szép et al. 2012).

\section{a) Activated sludge process}

Wastewater treatment systems that use activated sludge processes have been employed extensively throughout the world mostly because they produce effluents that meet required quality standards (suitable for disposal or recycling purposes) at reasonable operating and maintenance costs.

Conventional activated sludge with a long hydraulic retention time (HRT) has historically been the method of choice for the treatment of pharmaceutical industry wastewater. It has a lower capital cost than more advanced treatment methods and a limited operational requirement; it is generally more environmentally friendly than chlorination. However. high energy consumption. the production of large amounts of sludge and operational problems including colour. Foaming and bulking in secondary clarifiers are associated with activated sludge plants. Factors which affect the efficiency of activated sludge facilities for the treatment of pharmaceutical wastewater include HRT Temperature $\mathrm{pH}$. Dissolved oxygen (DO). organic load. Microbial community. presence of toxic or recalcitrant substances and the batch operation of pharmaceutical production facilities. These variables require modification for adaptation to pharmaceutical industry wastewater. Temperature is a key factor in the efficiency of activated sludge facilities. It has an important role in selecting individual microbial species and overall microbial diversity in the activated sludge(Feng et al. 2013; Gupta et al. 2006). This is where industrial wastewater can be very different from municipal wastewater. Therefore water from high temperature processes must be cooled prior to treatment by AS. Which increases the time and cost of treatment.

\section{b) Extended aeration}

In extended aeration process at a low organic loading long aeration time high MLSS (Mixed Liquor Suspended Solids) concentration and low F/M(Food Micro Organisms ratio). The BOD removal efficiency is high because of high detention in the aeration tank the mixed liquor solid undergo considerable endogenous respiration and get well stabilized. The excesses sludge dose not requires separate digestion and can be directly dried on sand beds. Also the excess sludge production is minimum. The performance of the ASP has been found to be more efficient when operating on an extended aeration basis. 
The design parameters of the process were evaluated for the treatment of combined wastewater from a pharmaceutical and chemical company in North Cairo that produced drugs. Diuretics and laboratory chemicals. The study revealed that at an extended aeration period of 20 hours(Laera et al. 2011). COD and BOD removal efficiency ranges of 89 to95\% and 88 to $98 \%$. respectively. In contrast. The performance of an extended aeration system for the treatment of pharmaceutical wastewater at was poor. By varying the F/M (food to microorganism) ratio and hydraulic retention time (HRT) the optimum conditions for obtaining an efficient system in terms of COD removal in treating the pharmaceutical waste is selected. The BOD removal efficiency is high.

\section{c) Oxidation ditch}

An oxidation ditch is a modified activated sludge biological treatment process that utilizes long solids retention times (SRTs) to remove biodegradable organics. The performance of an oxidation ditch for treating pharmaceutical wastewater has been evaluated and described by many researchers(Roskopf 1972). Treatability of wastewater from a typical pharmaceutical industry at Bombay producing various types of allopathic medicines was studied in an oxidation ditch at HRTs ranging from 1 to 3 days corresponding to an SRT (solid retention time) of 8-16 days. Oxidation Ditch Process showed a removal efficiency in the range of 86 to $91 \%$ for COD removal and about $50 \%$ for phenol removal. Considering the high COD/BOD ratio of the wastewater it has been suggested that the biological treatment should be supplemented with chemical treatment for this type of plant wastewater

\section{d) Trickling filter}

Trickling filters or activated sludge processes are used for treating municipal wastewater in plants that typically remove 80 to 90 percent of the carbonaceous BOD in the summer and 70 to 80 percent in the winter. Although a trickling filter plant is generally less efficient than an activated sludge plant a trickling filter requires less operator skill and attention(Lahiri et al. 2002). The performance of a trickling filter has been studied by many researchers and it was found that a high-rate trickling filter was capable of treating wastewater containing diversified fine chemicals and pharmaceutical intermediates to a level of effluent BOD less than $100 \mathrm{mg} / \mathrm{L}$. It has also been reported that wastewater from a pharmaceutical plant manufacturing antibiotics vitamins and sulfa drugs can be treated by using trickling filter. One study evaluated the efficiency of a sand bed filter for the treatment of acidic waste streams from a synthetic organic pharmaceutical plant at Hyderabad. The acidic waste stream was neutralized to a $\mathrm{pH}$ of 7.0 and treated separately through a sand bed filter. The sand bed filter was efficient in treating the acidic waste stream to a level proposed for its discharge to municipal sewer.The efficiency of the biological filter (trickling filter) for treatment of combined wastewater from a pharmaceutical and chemical company in North Cairo has been evaluated. The treatment system consisted of a biological filter followed by sedimentation. The degree of treatment was found quite variable. The study revealed that a biological filter alone was unable to produce effluents to a level complying with the national standards regulating wastewater disposal into the surface water.

\section{e) Membrane bioreactor}

Membrane Bioreactor (MBR) process consists of a biological reactor integrated with membranes that combine clarification and filtration of an activated sludge process into a simplified single step process. The membrane is an absolute barrier to suspended matter and microorganisms and it offers the possibility of operating the system at high mixed liquor suspended solids (MLSS) concentration(Patil et al. 2013). The implication of maintenance of high MLSS are requirement of a smaller footprint and operation at high solids retention time (SRT) under low $\mathrm{F} / \mathrm{M}$ ratio hence yielding reduced excess sludge. Operating as an MBR allows conventional activated sludge plants to become single step processes which produce high quality effluent potentially suitable for reuse. Application of MBR technology for industrial wastewater treatment has also gained attention because of the robustness of the process With more serious environmental pollution. The membrane bioreactor is operated similar to a conventional activated sludge process but without the need for secondary clarification and tertiary steps like sand filtration. Low-pressure membrane filtration either microfiltration or ultrafiltration is used to separate effluent from activated sludge. Due to the absence of a secondary clarifier the overall MBR plant size can be remarkably reduced in comparison with that of the conventional activated sludge process. MBR provides not only complete retention of all microorganisms and an increase of sludge concentration but also a complete disinfection of treated water. As a consequence MBR makes hydraulic retention time independent from sludge retention time which facilitates a more flexible control of operation parameters. High sludge concentration maintained in the bioreactor of the MBR makes it possible to treat high strength wastewater efficiently.

\section{f) Sequencing batch reactor}

Sequencing Batch Reactor (SBR) is a single vessel reactor with activated sludge system which operates in time rather than in space. SBR is fill and draw type system used for treating wastewater. SBR is used to treat the wastewater from industrials(Martz M. 2012). SBR is operated for different operating conditions. SBR is found to be low cost efficient and flexible technology which can be atomized in treating different industrial wastewater. optimization of SBR operating conditions for treatment of high strength pharmaceutical wastewater is studied. Two reactors of 1.5 litres supplied with air pump air diffuser are utilized. The reactors are fed by nonpenicillin pharmaceutical wastewater mixed with domestic 
wastewater in ratios 25:75 50:50 75:25. The HRT was varied for $12 \quad 24 \quad 48$ hours mixed liquor suspended solids concentration was varied $6000 \mathrm{mg} / \mathrm{l} 4000 \mathrm{mg} / \mathrm{l}$ at DO concentration $3 \mathrm{mg} / \mathrm{l}$. SBR achieved 94\% BOD5 removal and $83 \%$ COD removal at 24 hours HRT and $4000 \mathrm{mg} / \mathrm{l}$ of MLSS(Luan et al. 2012).

\section{Conclusion}

The occurrence and fate of pharmaceuticals in the environment and in aquatic media in particular have received considerable attention by the scientific community during the last two decades. There are various conventional treatment processes available for treating pharmaceuticals in waste water. In addition there are a number of promising new treatments including AOPs such as oxidation ozonation $\mathrm{TiO} 2$ photocatalysis Fenton reactions and ultrasonic irradiation. These significantly enhance the removal rate of pharmaceuticals from wastewaters. Comparisons among these technologies are problematic since most researchers used synthetic water rather than actual wastewater samples. Research is required in this area to improve treatment efficiencies identify degradation compounds and to determine the cost and feasibility of full-scale applications. From a practical point of view treatment-at-source may be a realistic option in (i) drinking water plants where ground and surface waters can be chemically oxidized to achieve destruction of pharmaceuticals micro pollution as well as disinfection and (ii) pharmaceuticals manufacturing plants where formulation effluents are generated. Given the relatively high concentration of organics in such effluents a process train comprising chemical and biological oxidation may be technically and economically feasible. Conversely pharmaceuticals found in the outlet of municipal WWTPs may not require immediate attention regarding pharmaceuticals removal since these streams are typically disposed of in watercourses and the sea. Nevertheless treatment-at-source may still be a plausible option replacing conventional chlorination by an AOP induced disinfection/oxidation technique.

\section{Disclosure statement}

No potential conflict of interest was reported by the author(s).

\section{References}

[1] Ashfaq A. and Khatoon A. (2014). Evaluating toxicological effects pollution control and wastewater management in pharmaceutical industry. International Journal of Current Research and Academic Review of 2 54-65.

[2] Balamurugan P. Shunmugapriya and Vanitha (2020a) GIS Based Assessment of Ground Water for Domestic and Irrigation Purpose in Vazhapadi Taluk Salem Tamil Nadu India Taiwan Water Conservancy 68(2) 1-10.
[3] Balamurugan P. and Balakumaran S. (2015). Soil quality assessment around magnesite mines and salem township using GIS techniques. International Journal of Advances in Engineering and Technology 8(1) 1997.

[4] Balamurugan P. and Kumar P. S. (2016). Quality of ground water assessment in Salem District using GIS Techniques. Advances in Natural and Applied Sciences 10(3) 22-32.

[5] Balamurugan P. and Shunmugapriya K. (2019). Treatment of Urinal Waste Water using Natural Coagulants. International Journal of Recent Technology and Engineering (IJRTE) Volume-8 Issue 355-362.

[6] Balamurugan P. and Vinnilavu G. (2020b). Removal of Methyl Violet Dye from Industrial Waste Water Using Neem Leaf Powder. Indian Journal of Ecology 47(2) 442-445.

[7] Balamurugan P. Kumar P. S. and Shankar K. (2020c). Dataset on the suitability of groundwater for drinking and irrigation purposes in the Sarabanga River region Tamil Nadu India. Data in brief 29 105255 https://doi.org/10.1016/j.dib.2020.105255

[8] Balamurugan P. Kumar P. S. Shankar K. Nagavinothini R. and Vijayasurya K. (2020d). NonCarcinogenic risk assessment of groundwater in southern part of salem district in Tamilnadu India. Journal of the Chilean Chemical Society 65(1) 4697-4707. http://dx.doi.org/10.4067/S071797072020000104697

[9] Balamurugan P. Priya G. S. and Arunkumar S. (2018). Design of systems for recycling of wastewater for sustainable development. International Journal of Civil Engineering and Technology (2) 9 955-962.

[10] Barker M. (2006). Pharmaceuticals Industry Water and Wastewater Treatment. Industrial WaterWorld 30-31.

[11] Chelliapan S. and Sallis P. J. (2013). Removal of organic compound from pharmaceutical wastewater using advanced oxidation processes. J. Sci. Ind. Res 72 248-254.

[12] Deegan A. M. Shaik B. Nolan K. Urell K. Oelgemöller M. Tobin J. and Morrissey A. (2011). Treatment options for wastewater effluents from pharmaceutical companies. International Journal of Environmental Science and Technology 8(3) 649666.

[13] Elmolla E. S. Ramdass N. and Chaudhuri M. (2012). Optimization of Sequencing Batch Reactor Operating Conditions for Treatment of High- 
strength Pharmaceutical Wastewater. Journal of Environmental Science and Technology 5(6) 452.

[14] Esplugas S. Bila D. M. Krause L. G. T. and Dezotti M. (2007). Ozonation and advanced oxidation technologies to remove endocrine disrupting chemicals (EDCs) and pharmaceuticals and personal care products (PPCPs) in water effluents. Journal of Hazardous Materials 149(3) 631-642.

[15] Félicien Mazille.Dorothee Spuhler. Advanced Oxidation Processes. Sustainable sanitation and water management.

[16] Feng L. van Hullebusch E. D. Rodrigo M. A. Esposito G. and Oturan M. A. (2013). Removal of residual anti-inflammatory and analgesic pharmaceuticals from aqueous systems by electrochemical advanced oxidation processes. A review. Chemical engineering journal 228 944-964.

[17] G upta S. K. Gupta S. K. and Hung Y. T. (2006). Treatment of pharmaceutical wastes. chapter 5167 233.

[18] García-Gómez C. Drogui P. Zaviska F. Seyhi B. Gortáres-Moroyoqui P. Buelna G. ... and UlloaMercado R. G. (2014). Experimental design methodology applied to electrochemical oxidation of carbamazepine using $\mathrm{Ti} / \mathrm{PbO} 2$ and Ti/BDD electrodes. Journal of Electroanalytical Chemistry 732 1-10.

[19] Gunasekera M. Abeygunawardana I. de Alwis A. and Pathirana W. (1998). Characterization of liquid effluent from a pharmaceutical production facility. Paper 59 of Session 6. In International Water Management Institute Conference Papers (No. h023506).

[20] Jelić A. Gros M. Petrović M. Ginebreda A. and Barceló D. (2012). Occurrence and elimination of pharmaceuticals during conventional wastewater treatment. In Emerging and priority pollutants in rivers (pp. 1-23). Springer Berlin Heidelberg.

[21] Joshua Amarnath D.Thamilamudhan R. Rajan S. (2015). Comparative study on wastewater treatment using activated sludge process and extended aeration sludge process. Journal of Chemical and Pharmaceutical Research7(1):798-802

[22] Kanakaraju D. Glass B. D. and Oelgemöller M. (2014). Titanium dioxide photocatalysis for pharmaceutical wastewater treatment. Environmental chemistry letters 12(1) 27-47.

[23] Klavarioti M. Mantzavinos D. and Kassinos D. (2009). Removal of residual pharmaceuticals from aqueous systems by advanced oxidation processes. Environment international 35(2) 402-417.

[24] Kommineni S.; Zoeckler J. Stocking A. Liang S.Flores A. Kavanaugh M. (2008) Advanced oxidation process. National Water Research Institute.

[25] Kumar P. S. and Balamurugan P. (2018). Evaluation of groundwater quality for irrigation purpose in Attur taluk Salem Tamilnadu India. Water and Energy International 61(4) 59-64.

[26] Kumar P. S. and Balamurugan P. (2019). Suitability of Ground Water for Irrigation Purpose in. Omalur Taluk Salem Tamil Nadu India. Indian Journal of Ecology 46(1) 1-6.

[27] Kumar P. S. Kumar and S. A. and Balamurugan P. (2016). Comparative studies on application of various adsorbents in fire industry waste water. Advances in Natural and Applied Sciences 10(3) 49-58.

[28] Laera G. Chong M. N. Jin B. and Lopez A. (2011). An integrated MBR-TiO 2 photocatalysis process for the removal of Carbamazepine from simulated pharmaceutical industrial effluent. Bioresource technology 102(13) 7012-7015.

[29] Lahiri S. Khan S. T. Mukkanti D. Akella V. R. and Anjaneyulu Y. (2002). Aerobic stabilisation of pharmaceutical wastewaters using large scale extended aeration activated sludge process.

[30] LaPara T. M. Nakatsu C. H. Pantea L. M. and Alleman J. E. (2001). Aerobic Biological Treatment of a Pharmaceutical Wastewater:: Effect of Temperature on COD Removal and Bacterial Community Development.Water Research 35(18) 4417-4425.

[31] Luan M. Jing G. Piao Y. Liu D. and Jin L. (2012). Treatment of refractory organic pollutants in industrial wastewater by wet air oxidation. Arabian Journal of Chemistry.

[32] Martz M. (2012). Effective wastewater treatment in the pharmaceutical industry. Pharmaceutical Engineering 32(6) 48-62.

[33] Munter R. (2001). Advanced oxidation processescurrent status and prospects. Proc. Estonian Acad. Sci. Chem 50(2) 59-80.

[34] Nithyanandam R. and Saravanane R. (2013). Treatment of pharmaceutical sludge by Fenton oxidation process. International Journal of Chemical Engineering and Applications 4(6) 359.

[35] Panneerselvam B. Karuppannan S. and Muniraj K. (2020a). Evaluation of drinking and irrigation suitability of groundwater with special emphasizing the health risk posed by nitrate contamination using nitrate pollution index (NPI) and human health risk assessment (HHRA). Human and Ecological Risk Assessment: An International Journal 1-25. https://doi.org/10.1080/10807039.2020.1833300 
[36] Panneerselvam B. Paramasivam S. K. Karuppannan S. Ravichandran N. and Selvaraj P. (2020b). A GISbased evaluation of hydrochemical characterisation of groundwater in hard rock region South Tamil Nadu India. Arabian Journal of Geosciences 13(17) 1-22.https://doi.org/10.1007/s12517-020-05813-w

[37] Parmar. R.B. and Patel. R.S. and Mistry.K.P. (2015) Review on waste water effluents from pharmaceutical companies. Indian journal of applied research 5(2) 221-223

[38] Patil P. G. Kulkarni G. S. Kore S. S. and Kore S. V. (2013 August). Aerobic sequencing batch reactor for wastewater treatment: a review. InInternational Journal

[39] Radjenovic J. Petrovic M. and Barceló D. (2007). Analysis of pharmaceuticals in wastewater and removal using a membrane bioreactor. Analytical and bioanalytical chemistry 387(4) 1365-1377.

[40] Roskopf R. F. (1972). Trickling filter-activated sludge combinations for domestic wastewater treatment.

[41] Shariati F. P. Mehrnia M. R. Salmasi B. M. Heran M. Wisniewski C. and Sarrafzadeh M. H. (2010). Membrane bioreactor for treatment of pharmaceutical wastewater containing acetaminophen. Desalination 250(2) 798-800.

[42] Shunmuga Priya and P. Balamurugan (2020) Experimental Investigation On Municipal Wastewater Treatment By Using Murraya koenigii Leaves As A Coagulant Indian Journal of Environmental Protection 40(8) 892-896.

[43] Szép A. Kertész S. László Z. Szabó G. and Hodúr C. (2012).Advanced treatment of pharmaceutical wastewater by nanofiltration and ozonation. Acta Technica Corviniensis-Bulletin of Engineering 5(1) 25.

[44] Tchobanoglous G. Burton F. L. and STENSEL D. (1991). Wastewater Engineering (Treatment Disposal and Reuse) New York Metcalf and Eddy. Inc. p 1334.

[45] Varatharajan B. and Kanmani S. (2007). Treatability study of pharmaceutical wastewater by combined solar photo Fenton and activated sludge process. J. Ind. Pollut. Control 23 157-164.

[46] Vinnilavu G. and Balamurugan P. (2019). Colour removal using neem leaf powder. Indian Journal of Environmental Protection 39(12) 1148-1153. 